\title{
A preservação dos modos de vida: a experiência da comunidade rural de Pedra Branca, município de Ipatinga/MG
}

Carolina Pereira Soares *

\section{Resumo}

Este artigo propõe uma reflexão sobre a ampliação do conceito de patrimônio cultural e a consequente complexificação das estratégias de salvaguarda. Ele enfoca a problemática em torno da noção de patrimônio imaterial, e propõe encará-la como uma nova postura frente à preservação dos bens culturais em seu conjunto. Neste contexto o tema do desenvolvimento local conquista espaço como importante ferramenta de promoção cultural, a qual, no entanto, precisa ser considerada com cautela. A fim de ilustrar as potencialidades imersas no fomento aos sistemas produtivos tradicionais como estratégias de preservação do patrimônio imaterial, o artigo apresenta a experiência da comunidade rural de Pedra Branca/lpatinga, MG.

Palavras-chave: Patrimônio imaterial. Desenvolvimento local. Preservação de bens culturais.

The preservation of traditional ways of life: the experience of the community of

\section{Pedra Branca}

\begin{abstract}
Focusing on the problem of intangible heritage, this article proposes an enlargement of the concept of cultural heritage, and the consequent complexification of related conservation policies., In this approach, local development becomes an important tool for cultural promotion, which, however, must be carefully considered. The relationship between intangible heritage and traditional systems of production will be illustrated by the experience of the community of Pedra Branca/lpatinga, MG.
\end{abstract}

Key-words: Intangible heritage. Local development. Preservation policies. 


\section{Introdução}

Este artigo consiste em uma reflexão acerca da ampliação e da complexificação da noção de patrimônio cultural, manifesta no conceito de bem intangível. Ele enfoca a construção de um novo aporte sobre os bens culturais, o qual extrapola a valoração estética e histórica tradicionalmente conferida ao patrimônio.

O texto enfatiza algumas importantes repercussões desse novo aporte sobre as políticas de preservação consideradas em sentido amplo, ou seja, contemplando o rol dos bens tangíveis e intangíveis. Neste contexto, o problema do fomento ao desenvolvimento local torna-se tema recorrente.

O artigo organiza-se em cinco partes, as quais conduzem a reflexão sobre o processo de complexificação da salvaguarda patrimonial. Na primeira, o texto enfoca a trajetória de ampliação da noção de patrimônio a partir da sucessão de três documentos principais: as cartas de Atenas, Veneza e Washington, que se relacionam entre si numa proposta de atualização. A segunda parte aborda as repercussões dessa trajetória no contexto brasileiro, no qual a preservação sistemática nasceu afinada com a Carta de Atenas, mas se complexificou gradativamente numa série de documentos, legislações e experiências. $O$ terceiro tópico do artigo problematiza a definição de patrimônio imaterial, apontando que o mesmo reflete, mais que uma nova categoria de bens, uma nova postura a ser assumida pelas estratégias de preservação em geral. A quarta parte aprofunda as reflexões anteriores, explicitando a relação entre desenvolvimento e preservação patrimonial e problematizando a noção de sustentabilidade. O último tópico do artigo é dedicado à apresentação da experiência de promoção dos modos de vida tradicionais em Pedra Branca, povoado da zona rural do município de Ipatinga/MG.

\section{Deslocamentos no conceito de patrimônio cultural}

O século 20 assistiu a um alargamento considerável da noção de patrimônio cultural, a qual, partindo do conceito de "monumento de excepcional valor histórico, artístico ou científico", culminou no advento da noção extremamente ampla, complexa e polêmica de bem imaterial.

A trajetória desta ampliação conceitual é particularmente explícita na sucessão das 
Cartas de Atenas, de 1931, de Veneza, de 1964, e de Washington, datada de 1986. O primeiro documento, um marco das pioneiras orientações de caráter internacional dedicadas à preservação do patrimônio, é complementado pela Carta de 1964, a qual foi posteriormente incrementada pelo documento de Washington.

A Carta de Atenas refere-se, principalmente, à conservação de edifícios, tratados como monumentos de interesse histórico, artístico ou científico. Propunha-se resgatar o tecido decomposto pela guerra mundial, a morfologia urbana das paisagens depredadas, e, nesse sentido, a cidade era tratada como cenário, especialmente para os monumentos, aos quais conferia ambiência.

Tendo por base este documento, a principal contribuição da Carta de Veneza consistiu em ressaltar que a noção de monumento não se restringia apenas às grandes obras, mas abrangia também as expressões arquitetônicas e urbanas consideradas menores. Nas palavras do documento de 1964,

a noção de monumento histórico compreende, além da obra arquitetônica em si, os sítios urbanos e rurais, testemunhos de uma civilização determinada, de uma evolução significativa e de um fato histórico. Compreende as grandes criações, e também as obras modestas, que, através do tempo, adquiriram valor cultural significativo. (CURY, 2000, p. 92).

Mas este documento pouco acrescentou à Carta de Atenas com relação ao problema da conservação urbana. Nele, a cidade ainda era tratada como um monumento no qual se enfatizava a morfologia, ou como mera ambiência para a arquitetura.

Foi a Carta de Washington que inaugurou contribuições mais significativas na questão da preservação de cidades e de sítios históricos. Ela se direcionava a um contexto político/social em que a deformação dos sítios tradicionais não se dava por efeitos demolidores da guerra, como nos dois documentos citados anteriormente. Ela visava sanar uma tendência de destruição e descaracterização desses espaços, tanto em seus aspectos morfológicos quanto funcionais, ocasionada por um modelo de desenvolvimento urbano predatório ao meio ambiente. Nessa perspectiva, a Carta de Washington extrapolava a mera consideração da espacialidade do sítio, a 
qual materializava a história e as preferências estéticas de cada período, e passava a enfocar, também, os aspectos intangíveis de sua dinâmica quotidiana.

Esta nova abordagem aproximou-se, assim, da noção contemporânea de patrimônio ambiental urbano (1), segundo a qual se busca preservar as qualidades ambientais do sítio, consideradas no sentido mais amplo de seus aspectos morfológicos e dos modos de apropriação dos espaços. Neste sentido, os usos que os cidadãos conferem aos lugares passam a ser valorizados como elementos que qualificam as cidades.

Este amplo enfoque demanda uma nova relação entre os especialistas e a sociedade com vistas à conservação urbana. Afinal, é preciso elaborar mecanismos para que os diversos modos de vida que qualificam os espaços sejam socialmente reproduzidos.

O campo aberto pelo enfoque ampliado da Carta de Washington repercutiu numa série de outros documentos internacionais que contemplam a preservação dos modos de vida, no novo conceito de patrimônio imaterial. Atualmente, seguindo esta tendência, o quadro contemporâneo é marcado pela formulação de vários manifestos em prol da diversidade cultural, como, por exemplo, a Declaração do México de 1985 e a Declaração Universal Sobre a Diversidade Cultural, da Unesco, de 2001. Nestes documentos, o enfoque ampliado extrapola as questões específicas da preservação patrimonial para abordar o tema mais amplo das políticas culturais.

\section{Apontamentos sobre a experiência brasileira}

A trajetória seguida pela noção de patrimônio cultural manifesta-se, no contexto brasileiro, em interessantes experiências de atuação institucional.

A história da conformação de uma política pública de preservação patrimonial no Brasil remonta à primeira década do século 20, com a fundação do Serviço de Patrimônio Histórico e Artístico Nacional/ SPHAN, atual IPHAN, através do Decretolei $n^{\circ} 25$ de 1937 . 
Afinado com a noção restrita de patrimônio então difundida pela Carta de Atenas, o SPHAN promoveu a preservação e restauração de vários sítios coloniais brasileiros, sendo Ouro Preto a experiência paradigmática do período. Em suas primeiras décadas de atuação, o SPHAN enfocou tais sítios numa perspectiva eminentemente estética, segundo a qual

[...] a identificação da cidade como monumento nacional não é nada mais que a extensão do princípio do monumento singular estendido a um complexo que, pela qualidade e pela somatória dos edifícios simples, adquire o valor de monumento global. (LOMBARDI, 1992, p. 81).

A literatura crítica atual identifica, nestas primeiras investidas do SPHAN, uma certa dose de negligência em relação aos aspectos intangíveis da dinâmica urbana, ou seja, aos modos de apropriação dos espaços pelos moradores locais. Naquele momento, a preservação dos sítios limitava-se à salvaguarda da morfologia urbana circunscrita ao centro-histórico, não cabendo, nos programas, a questão do desenvolvimento local, a qual abarcaria desde a promoção da cultura intangível dos habitantes até o problema da ocupação das periferias urbanas.

O debate nacional sobre a preservação patrimonial recebeu novos aportes ao longo dos anos 1960 e 1970, quando a noção de valor cultural significativo veiculada pela Carta de Veneza, nuançou os tradicionais critérios artísticos, históricos e científicos da Carta de Atenas. Neste contexto cabe mencionar a assinatura dos Compromissos de Brasília, em 1970, e de Salvador, em 1971, nos quais se reivindicava a descentralização da política pública nacional de preservação do patrimônio. Com isto, visava-se a promoção de ações mais plurais, sintonizadas com as peculiaridades dos diferentes Estados brasileiros. Para tanto, foram criados novos órgãos de preservação, como o Instituto Estadual do Patrimônio Histórico e Artístico de Minas Gerais, IEPHA/MG, instituído pela lei 5.775 de 1971, e atualmente regido pela lei 11.258, de 1993.

Nessa mesma época destaca-se, ainda, a atuação do Centro Nacional de Referência Cultural/CNRC, núcleo inicialmente autônomo e posteriormente inserido na estrutura do IPHAN. Sua atuação enfocou pesquisas voltadas para a o fomento ao artesanato tradicional, e nos legou uma contribuição conceitual importante, 
consagrando expressões como bem cultural, noção mais abrangente que a de patrimônio histórico e afinada aos debates da época, ou como patrimônio cultural não consagrado, na qual explicitava-se o viés político da eleição patrimonial.

Um outro marco importante na trajetória de ampliação da noção de patrimônio cultural no Brasil consiste no texto da Constituição Nacional de 1988. Neste documento cabe destacar 0 incentivo à descentralização das políticas de preservação patrimonial, fator essencial para a democratização das estratégias de promoção da cultura, tendo o município como ator privilegiado.

A Constituição de 1988 instalou, ainda, o conjunto dos bens intangíveis no debate público, forçando as políticas de preservação a se depararem com os desafios advindos com esse novo conceito. Em seu artigo 216 o documento definiu:

Constituem patrimônio cultural brasileiro os bens de natureza material e imaterial, tomados individualmente ou em conjunto, portadores de referência à identidade, à ação, à memória dos diferentes formadores da sociedade brasileira, nas quais se incluem: I - as formas de expressão; II - os modos de criar, fazer e viver; III - as criações científicas, artísticas e tecnológicas; IV - as obras, objetos, documentos, edificações e demais espaços destinados às manifestações artístico-culturais; V - os conjuntos urbanos e sítios de valor histórico, paisagístico, artístico, arqueológico, paleontológico, ecológico e científico. (BRASIL, 2001).

Nota-se, portanto, a construção gradativa de quadro institucional mais promissor ao debate em defesa da diversidade cultural, o qual contempla a complexidade imersa nas propostas de preservação dos modos de vida e dos sítios tradicionais.

\section{Repercussões da noção de patrimônio imaterial}

Conforme já mencionado, a trajetória de ampliação conceitual acima relatada trouxe à tona uma nova noção, a de bem intangível ou patrimônio imaterial, que vem se popularizando nos discursos e práticas de preservação.

Convém destacar, porém, que este novo enfoque inaugura uma série de desafios às políticas de salvaguarda, a começar pela própria delimitação de seu campo de atuação. $O$ universo de bens culturais contemplados pelo conceito de patrimônio imaterial não é facilmente definível, como à primeira vista pode parecer. A 
existência, no âmbito de instituições nacionais e internacionais, de duas linhas distintas de ação, uma voltada à salvaguarda do patrimônio tangível e outra à do patrimônio intangível, camufla a complexidade e a dificuldade de delimitação da categoria de bem imaterial.

A UNESCO, em sua Convenção para a Salvaguarda do Patrimônio Cultural Imaterial, de 2003, propõe uma definição de cunho meramente descritivo para o patrimônio intangível, enumerando os bens passíveis de comporem esta nova categoria:

[...] práticas, representações, expressões, conhecimentos e saber-fazer - assim como os instrumentos, objetos, artefatos e espaços culturais que a eles são associados - que as comunidades, os grupos e, eventualmente, os indivíduos reconhecem como compondo seu patrimônio cultural. (UNESCO, 2006, p. 4).

Neste conjunto são incluídos:

as tradições e expressões orais, nelas compreendida a língua como vetor do patrimônio cultural imaterial; as artes do espetáculo; as práticas sociais, rituais e os eventos festivos; os conhecimentos e práticas relativos à natureza e ao universo; os saber-fazer relativos ao artesanato tradicional. (UNESCO, 2006, p. 5).

Já para o patrimônio tangível não parece haver a mesma necessidade de definição por parte da UNESCO, o que sugere que tal classificação participa de um senso comum já estabelecido pela tradição do trabalho com as expressões culturais. Mas caberia buscar uma definição acessória na Convenção para a Salvaguarda do Patrimônio Mundial, Cultural e Natural, de 1972, que lida especificamente com os bens tangíveis, apesar de enfocar aqueles que expressem um valor excepcional universal. Na sua perspectiva, o patrimônio material consiste em:

monumentos: obras arquitetônicas, de escultura ou pintura monumentais, elementos ou estruturas de caráter arqueológico, inscrições, grutas e grupos de elementos (...); conjuntos: grupos de construções isoladas ou reunidas [...]; sítios: obras do homem ou obras conjugadas do homem e da na natureza, assim como as zonas em que se incluem os sítios arqueológicos [...]. (UNESCO, 1972, p. 2).

Tais descrições sugerem, portanto, a existência de duas categorias de bens culturais 
razoavelmente independentes, os materiais e os imateriais, as quais demandariam, cada qual, estratégias específicas para sua preservação.

Mas a relação entre bens tangíveis e intangíveis, e suas repercussões na formulação de estratégias de gestão e de promoção cultural, são mais complexas e sutis. Propomos explicitar este fato tomando por base uma distinção que escapa ao campo da mera enumeração, acima apresentada, para enfocar a relação estabelecida entre os bens culturais e os sujeitos que os praticam.

\footnotetext{
A distinção que cabe fazer, no caso dos bens culturais, é entre aqueles bens que, uma vez produzidos, passam a apresentar um relativo grau de autonomia em relação a seu processo de produção, e aquelas manifestações que precisam ser constantemente atualizadas por meio da mobilização de suportes físicos - o corpo, instrumentos, indumentária, e outros recursos de caráter material - o que depende da ação de sujeitos capazes de atuar segundo determinados códigos. (FONSECA, 2001, p, 22).
}

Neste sentido, o que qualifica o assim chamado patrimônio imaterial é, antes, a relação íntima, orgânica, que o mesmo estabelece com o contexto social que o promove e que dele usufrui. Podemos citar, como exemplo, uma festa de congado em algum povoado de Minas Gerais a qual depende, para sua realização, do interesse reafirmado da comunidade local. Em contraposição, a hipotética igrejinha que abrigaria a missa conga em homenagem à Nossa Senhora do Rosário se encontra numa situação mais estável, contando com maior autonomia em relação ao contexto social imediato. De um lado temos o novo conceito de patrimônio imaterial e, de outro, o tradicional rol dos bens materiais.

Mas o que propomos argumentar é que mesmo essa percepção de uma maior ou menor autonomia pode ser problematizada. Ela depende do enfoque que se confere ao bem cultural numa dada estratégia de preservação. Para esclarecer esta afirmação, talvez um tanto polêmica, tomemos como exemplo a diferença de atribuições existente entre o instrumento do tombamento, instituído pelo o Decretolei no 25/1937, e o do Registro Cultural de Lugares, instituído pelo Decreto no 3551/00. Em que se distinguem estes instrumentos quanto ao problema da preservação de bens, por exemplo, arquitetônicos? 
O Tombamento, instrumento que marcou a atuação do IPHAN, particularmente em suas primeiras décadas, incide sobre a materialidade da edificação, controlando sua alteração e impedindo descaracterizações. Em suas origens, ele vincula-se ao conhecimento acadêmico sobre a história da arte e da arquitetura e se justifica pela vinculação de uma dada edificação a um capítulo importante destas narrativas (2). Nesse sentido, o instrumento tradicionalmente impôs uma distinção entre as características morfológicas da edificação e as necessidades de uso e apropriação expressas pelo contexto social em que a mesma se insere. São as características físicas do imóvel que estarão protegidas para a posteridade, mantidas tal como o foram identificadas e valorizadas pela construção da história da arte.

Sabemos que Registro Cultural de Lugares age de forma diversa. Ao registrar uma edificação, por exemplo, o que se privilegia não é a conservação da sua materialidade e morfologia, mas a promoção dos modos de apropriação a que a mesma é submetida pelo contexto social imediato. O foco se volta, portanto, para as relações estabelecidas entre o lugar e a manifestação cultural que nele ocorre. No Registro, é o próprio uso do edifício o que se busca promover, ou seja, é a sua imaterialidade que está em cena.

Este exemplo sugere que a perspectiva inaugurada pelo debate acerca da preservação dos bens intangíveis mobiliza a discussão sobre o patrimônio cultural em geral. Assim, as estratégias de preservação que contemplam os bens móveis ou imóveis encontram-se, hoje, profundamente influenciadas pela perspectiva inaugurada pela visada ao intangível. Trata-se de um novo aporte, bastante influenciado pelo debate antropológico, e que exige que se "[...] desloque o foco que ora incide sobre os produtos terminais para as componentes políticas do processo através do qual os eventos culturais são produzidos" (ARANTES, 1977, p. 164).

Nota-se, portanto, que desponta um novo processo de mudança no enfoque das políticas de preservação patrimonial, o qual privilegia o caráter processual inerente à produção e à fruição dos bens culturais. Em linhas gerais, essa nova perspectiva propõe, antes de tudo, compreender o universo de significados que sustenta a produção cultural, numa abordagem que extrapola a mera conservação das qualidades materiais de um determinado bem. Tem-se como meta, portanto, 
compreender como se processa a reprodução social das expressões culturais, consideradas estas num sentido amplo do qual participam a música, a culinária, os ritos, a arquitetura, ou mesmo a morfologia urbana.

Este debate sobre o patrimônio imaterial inaugura novos dilemas nas políticas de preservação cultural. Afinal, como promover um patrimônio que abarca estruturas tão complexas como os modos de vida tradicionais, sem encarar o problema do desenvolvimento? Aliás, são os próprios rumos e fins a serem conferidos ao desenvolvimento que assumem o palanque no debate contemporâneo.

\section{Novos dilemas do desenvolvimento}

Os desafios que já despontam nesse novo contexto apresentam-se, de forma mais explícita, ao contemplarmos os inúmeros manifestos em defesa da diversidade cultural que pontuam o debate internacional. O que textos como a Declaração do México de 1985 e a Declaração Universal da Unesco de 2001 sugerem é que o problema da preservação patrimonial extrapola, atualmente, qualquer limite delimitável temporal e espacialmente. Isso porque, como já foi mencionado, eles acenam para a preservação dos diferentes modos de vida tradicionais. Nesse sentido, defende-se a promoção de estruturas sociais extremamente complexas, imersas em redes políticas, econômicas e culturais que influenciam o processo de sua reprodução social.

Convém questionar: como intervir em um universo tão amplo e delicado como a dinâmica social de uma comunidade? E mais: como elaborar uma política de preservação que não repercuta na espetacularização das manifestações culturais? Afinal, o que significa preservar o patrimônio imaterial?

Os debates atuais em prol do desenvolvimento local sustentável podem sugerir algumas pistas para tais questões. Convém, porém, destacarmos que o conceito de sustentabilidade é um tanto quanto impreciso, apesar de intensamente popularizado. Trata-se de uma noção vaga, uma orientação de caráter geral que deve ser adaptada a contextos específicos. 
Nesse sentido, o conceito de sustentabilidade só adquire contornos mais definidos, capazes de orientar práticas de intervenção sobre a realidade, ao apontar para sujeitos e objetos específicos: "o que" será sustentável? "para quem"? "para quê"? Isso insere os sentidos conferidos ao mesmo num jogo de disputa de interesses, em que seus limites são continuamente recriados (3).

A importância de se questionar qual o sentido conferido ao termo desenvolvimento sustentável, no campo da preservação patrimonial, é particularmente visível quando enfocamos o problema do turismo. Afinal, são bastante difundidos os discursos que legitimam essa prática como geradora de divisas aos municípios e importante motor para as economias locais.

No plano internacional, isso pode ser exemplificado no interessante projeto Research on The Values of Heritage desenvolvido no Getty Conservation Institute (G.C.I.) ao final dos anos 1990. Sua visada ao turismo com vistas ao desenvolvimento sustentável transparece em orientações como a seguinte:

\footnotetext{
este não é o momento em que afirmaríamos que o valor histórico do sítio é mais importante que o seu valor recreativo. Antes, o que está sendo sugerido é uma avaliação do grau de importância de um valor particular (como único, importante, típico, etc) de um sítio quando comparado o mesmo valor em outros sítios análogos. (MASON, 2002, p. 24).
}

Nesta recomendação, o projeto visaria minimizar a concorrência de mercado entre bens culturais que oferecessem benefícios análogos aos possíveis consumidores. Ela busca evitar, portanto, a oferta de produtos com características similares, incentivando a diferenciação dos mesmos.

Mas esta visada ao turismo assume um viés bastante polêmico. Afinal, a sua avaliação sobre as qualidades culturais de um determinado sítio parece contaminada por uma lógica mercadológica, que orientaria as propostas de intervenção. Isso poderia repercutir, por exemplo, na preferência pelas obras que oferecessem maiores retornos financeiros, e não por aquelas que incidissem sobre os bens de maior relevância cultural para a comunidade.

No contexto brasileiro temos um exemplo paradigmático dos possíveis efeitos 
perversos do turismo cultural de massa: a espetacularização do bairro do Pelourinho, em Salvador.

Fruto de um gradativo processo de abandono pelo poder público, que remonta ao final do século 19, a deterioração física e social vivenciada no Pelourinho foi alvo de intervenções drásticas que propunham fomentar a atividade turística. Declarado patrimônio da humanidade em 1985, o local trouxe à cena pública o debate sobre a noção de gentrificação. As cidades de Paraty/RJ e Tiradentes/MG também exemplificam efeitos desse neologismo, que nomeia o processo de enobrecimento e de musealização do espaço urbano, geralmente acompanhado de uma reformulação drástica no quadro dos usuários e dos residentes locais.

As formas de fruição incentivadas por sítios como estes ilustra a noção de banalização secundária do patrimônio, cunhada pela pesquisadora Françoise Choay. Com esta expressão a autora nomeia uma certa homogeneidade induzida na espacialidade dos diferentes sítios históricos, graças à valorização de parâmetros internacionais de segurança, higiene, limpeza, iluminação e prestação de serviços que operam sua revitalização.

Mas, afinal, como promover os diferentes modos de vida, em estratégias de desenvolvimento local, sem folclorizar a cultura tradicional?

Talvez algumas pistas para a solução de questões como estas possam ser vislumbradas em debates internacionais que enfocam a relação entre diversidade cultural e desenvolvimento local numa lógica de mercado um tanto quanto transgressora, como o debate em defesa da soberania alimentar, por exemplo. Esta nova bandeira, bastante defendida no contexto dos Fóruns Sociais Mundiais, contempla as atividades de subsistência das comunidades rurais, enfocando a produção e o consumo de alimentos como expressões culturais legítimas que devam ser preservadas. Ela reconhece que as formas de subsistência material das comunidades concorrem para a sustentação das suas manifestações culturais, de seu patrimônio intangível, pois compõem um universo de relações sociais, econômicas e políticas que estão intimamente imbricadas com tais manifestações.

As possíveis contribuições de debates como este para o âmbito da preservação 
patrimonial são muito importantes. Elas explicitam o imenso potencial imerso em programas políticos aparentemente alheios ao campo cultural - como, por exemplo, o de subvenção pública à agricultura tradicional - na preservação dos modos de vida tradicionais.

A experiência de promoção da cultura da banana em Pedra Branca/MG ilustra este argumento. Ela se insere numa tendência de elaboração de projetos de desenvolvimento, apoiados nos saberes e potencialidades locais, que apontam para a possibilidade de se promover as manifestações tradicionais sem as recorrentes intervenções diretas sobre as atividades culturais já existentes.

\section{A experiência da comunidade de Pedra Branca}

O povoado de Pedra Branca situa-se na zona rural do município de Ipatinga, sendo sua principal atividade econômica a agricultura em moldes familiares.

À época da elaboração dos projetos de promoção ao desenvolvimento local, na década de 1990, a população compunha cerca de 200 famílias e enfrentava sérias dificuldades econômicas, sociais e ambientais. Este quadro comprometia a manutenção dos trabalhadores nas atividades rurais, impulsionando a migração para a sede industrial do município. Dentre os principais desafios vivenciados, notava-se a precariedade nas técnicas de plantio e de manejo dos alimentos, sérios problemas na infra-estrutura de abastecimento de água e coleta de esgotos, e consequente assoreamento de córregos com a destruição de matas ciliares.

Esta situação, que repercutia no baixo nível de renda da comunidade, inviabilizando a agricultura familiar, comprometia, ainda, a autoestima da população local, incapaz de se afirmar no cenário político, cultural e econômico do município. As repercussões deste quadro para a preservação da cultura e das tradições locais foram negativas. Afinal, toda uma forma de vida que conferia suporte às expressões culturais vinha sendo deslegitimada.

Um dos principais impulsos para a alteração dessa situação foi o fomento ao associativismo local, com a criação da Associação de Moradores de Pedra Branca, em 1990. Para tanto, a população local contou com o apoio da EMATER/MG, 
empresa de fomento à produção do pequeno agricultor, vinculada à Secretaria Estadual de Agricultura, Pecuária e Abastecimento.

Em 1992 foi concebido um evento com vistas a impulsionar a produção agrícola, incrementar a sociabilidade local e inserir a comunidade de Pedra Branca no cenário cultural do município: o Festival da Banana, fruta bastante comum na paisagem das montanhas do povoado. Nesta iniciativa, a Associação de Moradores de Pedra Branca contou com o apoio da Prefeitura de Ipatinga, a qual incorporou o evento na programação cultural que homenageia, anualmente, o aniversário da cidade. A EMATER forneceu assistência técnica aos produtores locais, tanto para a organização do evento quanto para o plantio e processamento da fruta em licores, doces e salgados.

Desde então, a festa vem se desenvolvendo anualmente, contando com crescimento considerável do público e repercutindo no fomento ao turismo rural. A aproximação da data mobiliza a comunidade nos diversos preparativos, sendo motivo de grande expectativa. O evento foi se dinamizando progressivamente, incluindo novas atividades relacionadas com a cultura local, como cavalgada, shows de bandas locais e concursos de comidas típicas. Ele repercutiu, portanto, no resgate e na promoção de outras expressões extremamente relevantes, como a culinária tradicional.

Ainda visando a promoção da agricultura familiar, foi desenvolvido um amplo projeto de recuperação ambiental e de capacitação técnica das famílias locais, culminando na criação, em 1998, da Cooperativa de Beneficiamento de Doces de Frutas. Este segundo projeto compunha o Programa Nacional do Meio-ambiente e o Programa Estadual de Sub-bacias Hidrográficas de Minas Gerais enfocando-se o Uso e Manejo Integrado de Recursos Naturais da Sub-bacia do Ribeirão Pedra Branca. Ele foi viabilizado através de convênio firmado entre os governos federal, estadual e municipal, com a participação da associação de moradores local. Neste projeto desenvolveram-se atividades de educação ambiental para alunos da rede municipal, professores, além da comunidade em geral, reflorestamento de matas ciliares e de topo do morro, melhoramento do sistema de abastecimento de água e coleta de esgotos, tendo sido construída, em esquema de mutirão, uma barragem e uma caixa 
d'água no local. Estes trabalhos foram acompanhados pela reformulação paisagística local, criando-se novos pontos de convivência num ambiente até então degradado pela depredação ambiental e pelo acúmulo de entulhos nos espaços públicos.

A Cooperativa de Beneficiamento de Doces de Frutas consistiu num importante instrumental para a capacitação da população rural, oferecendo noções de educação alimentar, contemplando questões de higiene e de manejo de alimentos, administração e gerenciamento, além fomentar o associativismo local. Atualmente esta cooperativa encontra-se paralisada, tendo sido levantada, como uma das razões, a própria flutuação do mercado, no qual a venda da fruta in natura tornou-se mais rentável que o processamento da mesma.

Mas a experiência adquirida com a cooperativa, bem como o sucesso do Festival da Banana, explicitou, para a comunidade de Pedra Branca, o potencial cultural, econômico e político imerso no modo de vida local. Tais experiências promoveram a atividade rural, e diversas expressões culturais a ela relacionadas, como meio de subsistência legítimo, capaz de garantir a qualidade de vida da população do povoado e, até mesmo, de se tornar referência nacional. A valorização dos produtos do campo repercutiu na autoafirmação da população do povoado frente ao município.

Este processo fomentou, inclusive, o resgate de um elemento tradicional na conformação da casa mineira: os antigos quintais. Antes das experiências relatadas, estes locais reservados ao cultivo e à produção de subsistência vinham sofrendo uma reformulação espacial, com a substituição das plantações por um piso impermeável e uma área de lazer, bem típicos de um referencial urbano. Após o fomento à atividade rural, estas antigas áreas de plantações foram readquirindo seu espaço na vivência doméstica das famílias.

A experiência de Pedra Branca sugere, portanto, que ao se intervir na produção tradicional da comunidade, todo um modo de vida a ela associado pode ser promovido, incluindo-se aí, a relação com o meio ambiente, as atividades culturais que pontuam o calendário das famílias rurais, as receitas, o convívio social local. 


\section{Conclusão}

O artigo propôs enfocar a ampliação e a complexificação da noção de patrimônio, contemplando particularmente as repercussões do debate acerca dos bens intangíveis na formulação de estratégias de promoção cultural, nas quais o tema do desenvolvimento torna-se essencial.

Este novo enfoque inaugura um interesse particular pelos processos de produção dos bens culturais, buscando-se compreender a gama de valores que concorrem para a criação dos mesmos. Assim, mais que a mera manutenção física dos referidos bens, busca-se promover a reprodução social dos valores e tradições que os sustentam. Trata-se, portanto, da promoção dos modos de vida tradicionais.

Neste sentido, a experiência vivenciada pelo povoado de Pedra Branca sugere reflexões interessantes acerca da preservação do patrimônio imaterial. Este exige, para a sua promoção, que se contemple toda uma delicada trama de relações que permeiam as variadas esferas da vida social.

É esse complexo jogo de relações que vem se firmando como objeto de intervenção das políticas de preservação atualmente. É a ele que se deve remeter quando se propõe refletir acerca da noção de patrimônio cultural na contemporaneidade.

\section{Notas}

(1) A noção de patrimônio ambiental urbano foi cunhada, no Brasil, na década de 1970, particularmente na obra do estudioso Ulpiano Bezerra de Menezes, e se popularizou no debate contemporâneo sobre o planejamento urbano. Sobre essa noção confira CASTRIOTA, 1999.

(2) Sabemos que, particularmente a partir da década de 1980, o tombamento passou a ser problematizado num contexto de politização da preservação patrimonial, o que promoveu um uso mais estratégico do instrumento. Assim, o mesmo não seria utilizado apenas por suas implicações técnicas, mas pela legitimidade conferida ao bem cultural inscrito num livro do tombo. Sobre o assunto confira FONSECA (1996).

(3) A fim de exemplificar a fluidez dessa noção, pode-se citar uma pesquisa desenvolvida por ASCELARD (1999), na qual são levantadas diversas balizas em que se apoiaria o discurso sobre a sustentabilidade aplicado ao contexto urbano: as noções de eficiência, de escala, de equidade, de auto-suficiência e de ética. Em linhas gerais, a matriz da eficiência se voltaria ao combate do desperdício material gerado pelo desenvolvimento; a matriz da escala defenderia um limite ao crescimento econômico, considerando sua pressão sobre o meio 
ambiente; a matriz da equidade articularia princípios de justiça social e de ecologia; a matriz da auto-suficiência defenderia a independência de economias locais dos fluxos do mercado mundial; a matriz da ética inseriria a apropriação social do mundo material num debate sobre os valores do bem e do mal.

\section{Referências bibliográficas}

ARANTES, Antônio Augusto. Cultura popular: conservadora? Revista de Ciências Sociais, Fortaleza, v. 8, ns. 1/2, p. 163-169, 1977.

ASCELARD, Henri. Discursos da sustentabilidade urbana. Revista Brasileira de Estudos Urbanos e Regionais, $\mathrm{v}$ 1, n. 1, p. 79-90, maio 1999.

AVRAMI, Erica; MASON, Randall; DE LA TORRE, Marta. Values and heritage conservation: research report. Los Angeles: The Getty Conservation Institute, 2000, 100 p. (Formato PDF). Disponível em: <http://www.getty.edu/conservation/publications/pdf_publications/alpha_title.html>. Acesso em: out. 2006.

BRASIL. Constituição da República Federativa do Brasil (1988). São Paulo: Atlas, 2001.

CASTRIOTA. Alternativas contemporâneas para políticas de preservação. Topos, Belo Horizonte, v. 1, n. 1, p. 134-138, 1999.

CHOAY, Françoise. A alegoria do patrimônio. São Paulo: UNESP, 2001.

CURY, Isabelle. (Org.). Cartas patrimoniais. Rio de Janeiro: IPHAN, 2000.

FONSECA, Maria Cecília Londres. Para além da pedra e cal: por uma concepção ampla de patrimônio. Revista Tempo Brasileiro, Rio de Janeiro, n. 147, p. 23-27, 2001.

FONSECA, Maria Cecília Londres. Da modernização à participação: a política federal de preservação nos anos 70 e 80. Revista do Patrimônio Histórico e Artístico Nacional, n. 24, p. 153-163, 1996.

ICOMOS. Declaração do México, $1985 . \quad$ (Formato PDF). Disponível em:

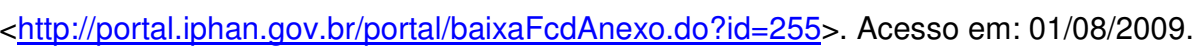

LOMBARDI, Giorgio. A cidade histórica como suporte da memória. In: CUNHA, Maria Clementina Pereira. (Org.). O direito à memória: patrimônio histórico e cidadania. São Paulo: DPH, 1992. p. 81-87.

MASON, Randall. Assessing values in conservation planning: methodological issues and choices. In: DE LA TORRE, Marta. (Ed.). Assessing the values of cultural heritage: research report. Los Angeles: The Getty Conservation Institute, 2002, p. 5-30, (Formato PDF). Disponível em: <http://www.getty.edu/conservation/ publications/pdf_publications/alpha_title.html>. Acesso em: out. 2006.

UNESCO. Convenção para a proteção do patrimônio mundial, cultural e natural, 1972. (Formato PDF). Disponível em: <http://unesdoc.unesco.org/images/0013/001333/133369por.pdf>. Acesso em: 01/08/2009. 
UNESCO. Declaração universal sobre a diversidade cultural, 2001. (Formato PDF). Disponível em: $<$ http://unesdoc.unesco.org/images/0012/001271/127160por.pdf>. Acesso em: 01/08/2009.

UNESCO. Convenção para a salvaguarda do patrimônio cultural intangível, 2006. (Formato PDF). Disponível em: http://unesdoc.unesco.org/images/0013/001325/132540por.pdf. Acesso em: 01/08/2009.

\section{Crédito}

* Graduada em arquitetura e urbanismo Universidade Federal de Minas Gerais (2002). Mestre em arquitetura pela Universidade Federal de Minas Gerais (2006). Arquiteta urbanista da Prefeitura Municipal de Belo Horizonte, atuando na Diretoria de Patrimônio Cultural da Fundação Municipal de Cultura. Docente no curso de arquitetura e urbanismo da Universidade Presidente Antônio Carlos UNIPAC/Campus Bom Despacho.

e-mail: carolina_psoares@yahoo.com.br 